\title{
FICCIÓN TELEVISIVA Y CONSTRUCCIÓN INTERGENERACIONAL DE MEMORIAS SOBRE EL PASADO RECIENTE EN CHILE
}

\author{
LORENA ANTEZANA BARRIOS ${ }^{1}$ \\ CRISTIAN CABALIN ${ }^{2}$
}

\begin{abstract}
RESUMEN
En este artículo, se presentan los hallazgos generales de una investigación cualitativa sobre la construcción de memoria sobre el pasado reciente de Chile. A partir del análisis de recepción de tres generaciones de telespectadores, se discute cómo las series de ficción televisivas producidas en el contexto de la conmemoración de los 40 años del golpe de Estado gatillan lecturas diferenciadas del pasado representado en ellas, en relación con la experiencia vivida de cada grupo de telespectadores. En estos resultados destaca, sobre todo, la «lectura intergeneracional» que propician las series a partir de un visionado crítico y activo.

PALABRAS CLAVES: MEMORIA, FICCIÓN TELEVISIVA, GENERACIONES.
\end{abstract}

${ }^{1}$ Periodista y Dra. en Información y Comunicación. Profesora asociada del Instituto de la Comunicación e Imagen de la Universidad de Chile. Correo electrónico: lantezana@uchile.cl

2 Periodista y Dr. en Estudios de Políticas Educacionales. Profesor asistente del Instituto de la Comunicación e Imagen y del Instituto de Estudios Avanzados en Educación, ambos de la Universidad de Chile. Investigador asociado de la Escuela de Gobierno y Comunicaciones de la Universidad Central de Chile. Correo electrónico: ccabalin@uchile.cl 


\title{
FICÇÃO TELEVISIVA E CONSTRUÇÃO INTERGERACIONAL DA MEMÓRIA SOBRE \\ O PASSADO RECENTE NO CHILE
}

\begin{abstract}
RESUMO
Neste artigo, são apresentadas as descobertas gerais de uma pesquisa qualitativa sobre a construção da memória sobre o passado recente do Chile. A partir da análise da recepção de três gerações de telespectadores, é discutido como as séries de ficção televisiva produzidas no contexto da comemoração dos 40 anos do golpe de Estado desencadeiam leituras diferenciadas do passado representado nelas, em relação à experiência vivida de cada grupo de telespectadores. Nestes resultados, destaca-se, principalmente, a «leitura intergeracional» que propiciam as séries de um visionamento crítico e ativo.

PALAVRAS-CHAVE: MEMÓRIA, FICÇÃO TELEVISIVA, GERAÇÕES.
\end{abstract}

\section{TELEVISION FICTION AND INTERGENERATIONAL CONSTRUCTION OF MEMORIES ON THE RECENT PAST IN CHILE}

\begin{abstract}
This article presents the general findings obtained from a qualitative research on the construction of memory on the recent past in Chile. On the basis of the analysis of the way that television fiction series produced in the context of commemorating 40 years of the military coup are received by three generations of TV viewers, it is discussed the way they trigger different readings of the past portrayed on them according to each viewer's experience. These results show a prominence of the «intergenerational reading» encouraged by series from a critical, active viewing.
\end{abstract}

KEYWORDS: MEMORY, TELEVISION FICTION, GENERATIONS. 


\section{INTRODUCCIÓN}

El 2013 se cumplieron cuarenta años del golpe de Estado en Chile. Fue un periodo que, al igual que en conmemoraciones anteriores, estuvo cargado de tensión y polémica, pero también de algunos acuerdos. Ya no se discutía sobre la violación a los derechos humanos, sino que sobre la (i)legitimidad del golpe, afectando la forma en que fueron leídos los acontecimientos de antaño.

Más que centrarnos en el debate y las disputas públicas planteadas, queremos en este texto prestar atención a una de las novedades de la conmemoración: la presentación en televisión abierta de programas ficcionales vinculados al golpe de Estado y la dictadura en tanto artefactos culturales de transmisión de memoria cultural, analizando la recepción de estas producciones en tres grupos de personas con experiencias de vida, en su niñez y juventud, disímiles: la de personas que vivieron el golpe de Estado (que al momento de la realización del primer año de esta investigación, el año 2016, tenían entre 50 y 64 años), la de quienes crecieron en dictadura (que al momento del trabajo de campo, el 2017, tenían entre 35 y 49 años) y la de los que crecieron en democracia (que al momento de consulta, el 2018, tenían entre 18 y 24 años). Catalogamos a cada uno de estos grupos como generaciones ${ }^{3}$ solo a nivel analítico y no conceptual, considerando simplemente su pertenencia a un determinado grupo etario con experiencias de vida similares.

Este artículo es parte de una investigación mayor ${ }^{4}$ que se preguntó por los tipos de memorias que construye cada grupo de telespectadores a partir de las propuestas de las series ficcionales y los repertorios iconográficos que utilizan para explicarse y entender ese pasado reciente. Aunque la pregunta por la transmisión de memorias no formó parte de los instrumentos de recolección utilizados (entrevistas en profundidad y grupos focales), es un tema que apareció en las respuestas precisamente por tratarse de relatos mediáticos y mediatizados.

\footnotetext{
${ }^{3}$ Sabemos que la discusión sobre el concepto «generación», desde los trabajos de Karl Mannheim, es amplia y está aún en construcción. En este artículo no profundizamos en esta discusión, pues los objetivos del estudio acá reseñados se concentran principalmente en la recepción televisiva.

${ }^{4}$ Proyecto Fondecyt Regular 2016, «Imágenes de la Memoria: Lecturas generacionales de series de ficción televisiva sobre el pasado reciente de Chile», $\mathrm{n}^{\circ} 1160050$.
} 
Aunque no fueron las únicas emitidas $^{5}$ en el marco de la conmemoración de los 40 años, trabajamos con las cuatro series ficcionales que tuvieron mayores índices de audiencia: Los archivos del Cardenal (transmitida por TVN, dos temporadas, periodo 2011-2014), Ecos del desierto (transmitida por Chilevisión, cuatro capítulos, 2013), No, la serie 6 (transmitida por TVN, cuatro capítulos, 2013-2014) y Los 80 (transmitida por Canal 13, siete temporadas, periodo 2008-2014). Estas series, construidas en formatos distintos, abordan aspectos específicos de la dictadura desde los más ficcionales - como Los 80, que relata la década a través del seguimiento de los Herrera, una familia de clase media que vive en Santiago de Chile, cuya vida cotidiana se desarrolla durante esa década, y Los archivos del Cardenal que, en formato policial, cuenta el trabajo realizado por profesionales de la Vicaría de la Solidaridad, que tenían como misión asesorar a las familias de las víctimas en la defensa de los derechos humanos durante la dictadura militar, inspirado en casos reales documentados - hasta los más cercanos a los acontecimientos registrados, en formato docudrama - como Ecos del desierto que se centra en la búsqueda que realiza la abogada Carmen Hertz de su marido, detenido desaparecido en 1973 por la Caravana de la Muerte ${ }^{7}$, y No, la serie, que aborda el proceso de creación de la franja televisiva y la campaña del $\mathrm{No}^{8}$ para el plebiscito de 1988.

En todos estos relatos, la estructura narrativa está pensada desde un punto de vista específico: el de quienes se opusieron a la dictadura; y las historias que se presentan están contadas desde la perspectiva de las víctimas y de quienes lucharon por recuperar la democracia.

${ }^{5}$ También se presentaron: Amar y morir en Chile. 2012, transmitida por Chilevisión en dos capítulos.

${ }^{6}$ Utilizamos esta denominación para distinguir esta producción de la película No, que fue la base de la serie del mismo nombre. La versión televisiva cuenta con cien minutos más que la película y fue realizada gracias al financiamiento otorgado por el Consejo Nacional de Televisión a través de un fondo concursable.

${ }^{7}$ Nombre dado a la comitiva encabezada por el general Sergio Arellano, responsable del asesinato de setenta y dos prisioneros en 1973, en el norte de Chile.

${ }^{8}$ En 1988 se realizó un plebiscito para aprobar (SÍ) o rechazar (NO) al candidato único nombrado por la Junta de Gobierno. El triunfo de la opción No permitió la realización de elecciones presidenciales y el fin de la dictadura. 
El 2013 también se presentaron en esos mismos canales televisivos catorce programas de esta temática de no ficción (entrevistas, reportajes periodísticos y documentales), tres de ellos en formato seriado como Chile: imágenes prohibidas (documental, transmitido por CHV, cuatro episodios), Los mil días (documental, transmitido por Canal 13, cuatro episodios) y 11 intimo (documental, transmitido por Canal 13, cuatro episodios) (Antezana, 2015). Los mencionamos, pues fueron parte del visionado sobre el tema que realizaron las y los telespectadores en ese periodo quienes, al hablar de las series, no solo podían mezclarlas entre ellas, sino que también incorporaban relatos provenientes de otras fuentes, entre ellas, esos otros programas.

\section{DECISIONES TEÓRICAS Y METODOLÓGICAS}

Las conmemoraciones, en gran medida, permiten volver a enfrentar públicamente pasados difíciles, vinculados a traumas, disputas, tensiones y conflictos, haciendo que la distancia histórica sea relativa. Estos pasados se hacen presentes a través de diversas fórmulas narrativas, una de ellas es la ficcional, que es la que aquí exploramos, en tanto «facilitan la aparición de historias generacionales como símbolos de continuidad o ruptura» (Frei, 2015: 2 ), que es lo que observamos en el relato de las y los telespectadores.

Las producciones ficcionales operan a nuestro modo de entender como soportes de memoria. Son un tipo de apoyo que también responde a la denominación de artefacto cultural junto con las emociones y las comunicaciones, «a través de los cuales se transmite, disputa y elabora el pasado» (Frei, 2015: 17). Es así que estas producciones se relacionan con la construcción de memoria colectiva, puesto que se caracteriza por su dependencia respecto del mundo material al necesitar objetos físicos $y$ estructuras para expresarse.

La memoria colectiva (Halbwachs, 2004; 1995) es, por tanto, un proceso continuo y multidireccional que está innegablemente conectado a un grupo social dentro de un contexto espacio-temporal. Esto, pues es a través de la formación y remodelación de las versiones sobre el pasado que los grupos sociales construyen una imagen de sí mismos que les permite diferenciarse del resto. Por esto, consideraremos a la memoria colectiva como un constructo social. 
Nuestras sociedades necesitan a los medios de comunicación para difundir estos soportes de memoria, socializar sus marcos de funcionamiento y organización; transmitir sus modelos y pautas de conducta deseables; establecer sus límites y, en general, construir un sentido de comunidad. Por esto hablamos de sociedades mediatizadas, en las que los medios se relacionan con la sociedad, la vida cotidiana y las estructuras de producción, entre otras.

De esta forma, la televisión puede ser entendida más que como una tecnología de difusión de productos audiovisuales, es un actor sociocultural (Santa Cruz, 2017), situado históricamente en una sociedad mediatizada, una en la que el conjunto de prácticas sociales se estructuran y cobran sentido en relación directa con los medios de comunicación (Antezana y Santa Cruz, 2016). Bajo esta premisa, la televisión sería un dispositivo que pone en circulación productos audiovisuales — artefactos - de carácter masivo, que no debiesen entenderse como una sumatoria de programas, sino más bien como un flujo discursivo que masifica propuestas «situadas» y cumple funciones de articulación social.

Para que este sistema opere, se requiere una sinergia entre la instancia de producción y la de recepción, que se relaciona con el género del discurso audiovisual. Son precisamente los productos seriados ficcionales - como las comedias de situaciones (soap operas), telenovelas y series, entre otras-, los que se han consolidado exitosamente en la programación televisiva, y han demostrado ser un buen vehículo para masificar relatos sobre el pasado, puesto que la recreación que realizan permite visualizar escenas «invisibles» (Feld, 2010), es decir, de las que no se tienen registros visuales y además actualizan acontecimientos pasados en un formato, personajes y tramas vinculados con el presente, lo que las hace más atractivas (Chicharro, 2011), sobre todo para las nuevas generaciones.

La ficción busca fundamentalmente entretener, por lo que, además de orientar sus propuestas hacia los gustos y hábitos de consumo de sus telespectadores ideales, debe propiciar su identificación (Castillo, Simelio y Ruiz, 2012), entendida como la experiencia de uno mismo a través de la experiencia del otro (Jauss, 1978), respondiendo a sus motivaciones cognitivas y afectivas (Sánchez, 2012).

Las series ficcionales con las que trabajamos construyen sus contenidos representándolos de manera verosímil y, para esto, utilizan variadas estrategias de veridicción (ambientación de época, personajes creíbles, lugares 
reconocibles, hitos históricos, etc.); a nivel afectivo, las series buscan establecer un vínculo entre los personajes y los telespectadores (Schlotterbeck, 2014), además operan bajo los parámetros establecidos por la cultura emocional (Bourdin, 2016) de los telespectadores: construyen un clima emotivo (utilizando música, luminosidad, manejo de cámaras, entre otros recursos estilísticos) que facilita la lectura afectiva de las distintas escenas, utilizando un repertorio gestual y corporal aprendido socialmente, entre otros recursos.

En cuanto al proceso de lectura de las series, este se realiza en un contexto sociohistórico que determina las condiciones de recepción, el clima social o sensibilidades de la época (Waldman, 2014) que, para la conmemoración de los cuarenta años del golpe de Estado en Chile, reconocía - como ya lo hemos anticipado - tanto la violación a los derechos humanos como su condena y donde los telespectadores sabían que las series estaban construidas desde el punto de vista de quienes fueron víctimas y/o se opusieron a la dictadura.

La relación que establecen las y los telespectadores con el producto audiovisual (serie ficcional) no es individual, aunque así lo parezca. Esto, pues ellas y ellos son parte de una «comunidad imaginada» (Anderson, 1993), en un sentido amplio ${ }^{9}$, es decir, son un conjunto de personas que comparten condiciones materiales que configuran una cultura común y de instituciones que facilitan su reproducción social - periódicos, novelas, censos, mapas, museos y otros-, papel que cumplen actualmente los medios masivos de comunicación, especialmente la televisión.

Entendemos entonces la recepción como un proceso efectuado por las audiencias en su interacción con la televisión que supone no solo un registro de lo que se está presentando, sino el diálogo entre esas propuestas y los conocimientos, huellas emocionales y experiencias que cada uno de los telespectadores posea (Antezana, 2015), al ser parte de comunidades interpretativas, entendidas como conjuntos «de sujetos sociales unidos por un ámbito de significación común» (Focás, 2014: 353).

La investigación aquí reseñada se propuso examinar cómo las personas de distintas generaciones recuerdan o se apropian de estos pasados difíciles a partir de sus experiencias de recepción de discursos públicos —en nuestro caso

\footnotetext{
${ }^{9}$ No solo centrado en la construcción de una nación.
} 
televisivos - inscribiendo este estudio en la segunda ruta de trabajo planteada por Frei (2015) en una estrategia de abajo hacia arriba, destinada a indagar en el impacto en las audiencias de estos artefactos culturales.

Por generación, entenderemos un grupo dentro de una sociedad que se caracteriza porque sus miembros han crecido compartiendo un marco epocal, sociohistórico, en una similar etapa de la vida (Dávila y Ghiardo, 2018), aunque sus ideas e interpretaciones sobre la misma sean diferentes, e incluso opuestas (Álvarez, 2018a). A menudo, «tal identidad generacional existe a lo largo de la vida de sus miembros debido a que han experimentado momentos de agitación radical y nuevos comienzos (principalmente en la adolescencia) y, como resultado, comparten un habitus específico (la "hipótesis de la impronta")» (Reulecke, 2008: 119).

Es lo mismo que ocurre con la construcción de memorias generacionales que se forman con el paso del tiempo y no simplemente nace en décadas y eventos fundamentales (Frei, 2015). Estas memorias son de naturaleza social, pues incluso los recuerdos considerados más personales «están inmersos en narrativas colectivas» (Jelin, 2001: 4). Estos recuerdos son huellas que solo se constituyen en memorias cuando son evocadas y ubicadas en un marco de interpretación que les da sentido (Halbwachs, 2004), que es precisamente lo que, junto a una serie de imágenes que representan esa realidad (Baer, 2006), movilizan las series.

La memoria, cuando se trata de la lectura de textos culturales, es la representación de un hecho o una situación mediante una acción interiorizada en el sujeto que es capaz de relacionar un estímulo externo con sus propios esquemas mentales. Esta memoria se expresa en representaciones comunes que se sostienen en la pertenencia a un determinado grupo, porque aun cuando las percepciones del pasado varían de acuerdo a quien recuerda, son comunes, pues tienen un origen social. La «experiencia» no depende directamente del acontecimiento, sino que está mediada por el lenguaje y el marco cultural interpretativo en que se expresa (Jelin, 2014).

La memoria contemporánea no se constituye solo a través de la recuperación o representación de algún contenido del pasado en el presente, sino que se mediatiza (Hoskins, 2014) a través de prácticas vinculadas con las tecnologías disponibles. Es así entonces que el valor de la misma no necesariamente está en su estabilidad y continuidad, sino que en su potencial de transformación. 
La memoria «coloniza» el pasado y lo organiza sobre la base de las concepciones y las emociones del presente (Sarlo, 2004: 50). En este sentido, las que se construyen son siempre memorias parciales e incluso antagónicas pues, aunque se trate de un mismo acontecimiento, no todas las personas les asignan los mismos significados y estos pueden ser incluso diferentes o contradictorios en una misma generación y, aún más, en generaciones distintas (Waldman, 2009), que es el caso de esta investigación.

Esto, entre otras cosas, se debe a la modificación de los marcos de interpretación (Halbwachs, 2004) disponibles que, al contar con más antecedentes y evidencia, van enriqueciéndose o modificando en el tiempo. Un marco de interpretación es el que permite organizar los distintos acontecimientos en un relato que tenga sentido, es decir, permite otorgarles un significado y leerlo desde algún punto de vista, puesto que se trata siempre de construcciones de sentido más o menos validadas y consolidadas por un conjunto social.

Existen, por tanto, varias memorias colectivas que se van transformando en la medida en que nuevas imágenes cubren a las antiguas (Halbwachs, 2004) y se van transmitiendo (de manera directa o no) entre las distintas generaciones. Nos referimos a los silencios, las omisiones y negaciones que también son parte de los procesos de transmisión de memorias traumáticas.

Al incluir en esta perspectiva el enfoque generacional, es posible conectar la identificación de las estructuras generales y los procesos especialmente los de varios niveles sociales-, con las percepciones y experiencias subjetivas de los contemporáneos, incluidas sus interpretaciones, esferas de acción y opciones para acciones. Con esto es posible lograr una disolución, al menos parcial, del par de opuestos demasiado enfatizados «objetivo vs. Subjetivo», a favor de una perspectiva integradora. Lo que sitúa la temporalidad concreta de las personas -incluyendo su «bagaje» generacional - en el contexto del cambio histórico general (Reulecke, 2008).

La investigación realizada se enmarca en los estudios de audiencia desarrollados en América Latina a partir de los años 90 -que vinculan los estudios culturales ingleses y la teoría crítica (Focás, 2014)—, por lo que entendemos que la recepción televisiva no solo está relacionada con la clase social de los telespectadores (Grossberg, 2009), con sus recursos culturales que en países tan desiguales como Chile están asociados también al nivel educacional (Contreras y Macías, 2002)—, o su género y necesidades 
específicas (Wolton, 2001), sino que también con las características contextuales y políticas en que estos procesos se insertan (Antezana y Cabalin, 2016).

El diseño de la investigación fue secuencial y de desarrollo (Greene, 2007). Esto quiere decir que las fases de la investigación se realizaron una tras otra y cada una nutrió la siguiente. Así, se realizaron ocho entrevistas que permitieron el desarrollo de dos grupos focales por cada una de las tres generaciones consideradas. Para la selección de personas entrevistadas realizamos un muestreo intencionado, considerando como telespectadores a todos quienes vieron una o más de las series mencionadas, además de la edad, el género y el grupo socioeconómico (GSE) ${ }^{10}$. Desarrollamos una entrevista interpretativa, que consiste en la realización de una conversación relativamente no estructurada y que nos permitió indagar en las percepciones, discursos, emociones y trayectorias de los sujetos de manera dialógica (Denzin, 2001).

Una vez realizadas las entrevistas, se analizó su texto transcrito. Para esto, empleamos el método de análisis temático, que consiste en «identificar, analizar y reportar los patrones de significado presentes en los datos» (Braun y Clarke, 2006: 79). No existió una teoría previa que guiara el análisis estableciendo categorías predefinidas, por el contrario, aplicamos una taxonomía inductiva, es decir, un sistema de clasificación de los datos de acuerdo a categorías emergentes (Sautu, 2004). Así se establecieron los ejes temáticos más relevantes - conceptos recurrentes o el conjunto de ideas que caracterizan la experiencia de los sujetos entrevistados (Bradley, Curry y Devers, 2007)-, organizados en cinco categorías analíticas: contexto de recepción, apreciación estética, contenido referencial, cuerpo o afectos, e imágenes. Esto nos permitió establecer los repertorios iconográficos de cada generación que fueron testeados en los grupos focales.

Para estos, nos interesó conformar una muestra heterogénea, asumiendo que el tema de la discusión provocaría controversias, posiciones disímiles y tensiones. Realizamos dos grupos focales por generación, uno con hombres y otro de mujeres. En ambos casos, los participantes tenían diferentes características socioeconómicas y también distintas afinidades políticas.

${ }^{10}$ Consideramos cuatro categorías: $\mathrm{ABC} 1$ (2.500 dólares o más de ingresos por hogar al mes); C2 (ingresos mensuales del hogar entre mil y dos mil dólares); C3 (hogares con ingresos mensuales entre seiscientos y ochocientos dólares) y DE (hogares con ingresos mensuales menores a quinientos dólares). 
Los resultados están organizados por generación y en tres niveles de análisis: individual, lo que significaron las series y su emisión para las personas consultadas; generacional, las repercusiones de la ficción y su utilidad en tanto colectivo, e intergeneracional, es decir, en función del diálogo y la construcción de memorias.

\section{PRIMERA GENERACIÓN: DEMOSTRAR Y ENSEÑAR}

A nivel individual, las personas de esta generación estaban dispuestas a ver las series televisivas ficcionales sobre el pasado reciente, por curiosidad sin duda, pero sobre todo para poder evaluar esos contenidos y su relación con lo que cada uno de ellos construye como realidad sobre ese pasado reciente, a partir de su propia experiencia y fundamentalmente en relación con su posición e ideología políticas. Esto, pues salvo en el caso de Los 80 en sus primeras temporadas $^{11}$ — consideradas menos políticas_-, las personas que optaron por ver las series se sentían más cercanas al punto de vista de la construcción de las mismas, es decir, como opositores a la dictadura o al menos autodefiniéndose en una posición neutral.

No todos los relatos ni todas las imágenes de ese periodo fueron parte de las propuestas ficcionales. Es así como las distintas visiones acerca de la dictadura entraron en conflicto y la disputa sobre este pasado es uno de los puntos nuevamente polémicos de la conmemoración de estos cuarenta años (Antezana y Cabalin, 2018; 2017). Las personas entrevistadas, a pesar de reconocer la importancia de no clausurar o cerrar el debate sobre la dictadura, tienen una opinión y postura ya formadas sobre la época y las series simplemente las refuerzan, en ningún caso las modifican.

Es por esto que la ficción televisiva opera en ellos/as como un estímulo, una oportunidad para abrir los diques de la memoria que, en muchos casos, traduce lo que algunos no logran decir y expresar, les permite compartir emociones y vivencias, y en definitiva son un pretexto para recordar su propia vida y su experiencia familiar durante la dictadura cívico militar. Dice una entrevistada: «Entonces, volver a ver la serial fue bueno, volver a vivir ese momento y a la vez, una puerta para abrir una puerta con los nuestros. Porque

${ }^{11}$ Los telespectadores reconocen que, a partir de la tercera temporada, la serie hace más explícita la situación política que se vivía en el país. 
fue fuerte, sobre todo el primer capítulo para mí fue fuerte y en lo personal, todo lo que pasó cuando veía la serie y se iban descubriendo todas esas cosas, uno se remontaba igual a la época, cuando estábamos ahí, cuando se encontraron los cuerpos, cuando tenías que esconder, hacer barretines en tu casa para poder guardar tus cosas, las revistas, los libros» (Mujer, C2).

A nivel generacional, es posible observar la extrema politización del campo de la memoria de ese periodo entre los miembros de esta generación, en instancias de discusión grupales - como durante la realización de nuestros grupos focales - y la tensión que aún persiste y se hace evidente en la conversación sobre estos temas. Así se hace explícito el «desacuerdo profundo» que divide y marca a muchas de las personas de este grupo. Durán (2016) indica que un desacuerdo profundo como el que se registra aquí no se puede resolver mediante el uso de argumentación, ya que la forma en que es comprendido el pasado reciente socava las condiciones esenciales para el argumento. Esto se debe a que este tipo de desacuerdo invoca algo que no existe: un acervo compartido de creencias y preferencias. Además, involucra la emoción que incide en el tipo de resolución del desacuerdo. Lo expresa así uno de los participantes: «O sea, te envuelven con esto [las series], como en la Caperucita Roja, te envuelven con un tema de la caperucita y después te aparece el mismo tema de politizar, de vender un concepto, una ideología, y ya no queremos más, ya realmente hemos sufrido muchísimo, muchísimo en todas épocas. Entonces, Chile está altamente dividido económicamente, ideológicamente» (Focus, hombres).

Esto permite explicar el rechazo de estas personas a conversar con sus pares sobre lo sucedido, salvo entre sus cercanos generacionalmente, que comparten sus puntos de vista. En ese sentido, las series televisivas inciden en esta generación, puesto que ponen en escena nuevamente la fuente de discordia que la transición a la democracia logró esconder y disimular, pero no resolver, y, de acuerdo a su ideología, pueden o no estar de acuerdo con las repercusiones que genera su emisión. Así, en nuestro grupo focal detectamos tres tipos de respuesta: a) la de quienes están de acuerdo con el punto de vista en que están construidos estos relatos ficcionales, pues sienten que los mismos validan su postura y opinión; b) la de quienes no están de acuerdo con este punto de vista y lo rechazan (la primera forma de manifestarlo fue elegir no ver alguno de estos programas o, en el caso de los que empezaron a verlos, cuestionar la parcialidad de estos relatos y dejar de verlos), y c), la de quienes desean dar vuelta la página y no abordar estas temáticas que «dañarían» al país. Estas tres 
posturas no lograron llegar a consenso y la única forma de resolverlo fue cambiar de tema, hablar de cuestiones cotidianas presentes en las series (sobre todo en $\operatorname{Los} 80$, considerada por los participantes como la más neutral al menos en sus primeras temporadas) y sobre la ambientación de la época y la calidad estética de la producción. La tensión se hizo mucho más evidente en el grupo de hombres que en el de mujeres.

Nuestros/as entrevistados/as, aun estando de acuerdo con la perspectiva de las series, cuestionan la simplificación excesiva de procesos más complejos (como el plebiscito en el caso de No, la serie, que es reducido a una estrategia publicitaria y de marketing) y la utilización de formatos (como el policial de Los archivos del Cardenal) que se centran en los personajes protagonistas heroicos, dejando fuera a otros actores importantes y que permanecen anónimos. Lo observamos en esta frase: «Porque estaba demasiado centrado en que el NO se había ganado en la campaña publicitaria, que desperfilaba, minimizaba todo el tremendo esfuerzo que se hizo para derrotar a la dictadura, que un montón de gente se reunió, marchó, en fin [...]» (Hombre, $\mathrm{ABC} 1$ ). Valoran, sin embargo, la propuesta de Ecos del desierto, que reconocen bastante cercana al relato original y validan al director de la misma, Andrés Wood, cuya producción previa - Machuca - mantiene una misma línea y reconocen el trabajo de ambientación y archivo en Los 80 .

La simplificación de los relatos - que responde, en principio, a las restricciones propias del formato televisivo y ficcional - para ellos/as termina materializando la idea de un país que parece saber reconstruirse y que, por tanto, puede seguir adelante. Así, las series serían instrumentos legitimadores de la transición política chilena ${ }^{12}$.

En cuanto a las posibilidades de transmisión intergeneracional de este tipo de producciones, más que para ellos - los participantes de esta generación que vivieron y conocen de primera mano lo ocurrido en ese periodo-, las series serían importantes para las otras generaciones, principalmente para sus hijos y para las personas - incluso dentro de su propia generación- que no creían, o no aceptaban, que algo así había ocurrido en el país, porque no tuvieron familiares o personas cercanas afectadas por la represión. Lo dice una participante: «Mis hijas no podían creer que hubiera pasado, una de ellas me

${ }^{12}$ Para mayores antecedentes véase Antezana \&y Cabalin (2017), donde se analizan las propuestas conciliadoras de los finales propuestos en las cuatro series. 
decía, "sabes, mami, no puedo creer que haya pasado esto en Chile", es como que tú te sientas a ver una película de Alemania, lo que pasó con los judíos y es como que no puedes creer que todo eso pasó ahí, y pasó» (Focus, mujeres).

El visionado de las series se fue convirtiendo poco a poco en una instancia familiar, en la que los hijos e hijas se fueron acercando a sus padres para preguntar acerca de lo que estaban mirando. Estos momentos de encuentro son destacados por quienes vieron las series porque les permitieron no solo hacer partícipes a sus familiares de lo que ellos vivieron, sino que también, de manera implícita, pedir comprensión sobre su forma de actuar en relación con ellos y, en algunos casos, fundamentar las razones del silencio que mantuvieron durante tanto tiempo. La emisión de las series fue un pretexto para poder conversar sobre sus vivencias en ese periodo con la siguiente generación.

En síntesis, las series tuvieron un valor documental para esta generación. No les muestran nada nuevo, pero les permiten recordar, son un estímulo para volver a traer al presente ciertas vivencias y experiencias y tener un pretexto para compartirlas con otros, para hablar de ello. Así, «florecen unas verdades subjetivas cuyo argumento es la rememoración de lo vivido» (Sarlo, 2004: 37). Permitieron también romper en alguna medida con la práctica generalizada del «silencio comunicativo» con respecto a la última dictadura, que se traduce en un «miedo a hablar sobre el pasado entre los grupos de más edad, un patrón cultural para evitar conflictos» (Frei, 2015: 20), pero también se trató de una oportunidad de demostrar a otros, cuya opinión sí les importa (sus hijos), la veracidad de sus recuerdos y vivencias, y de enseñar y compartir sus aprendizajes con las restantes generaciones. Así, las series y el momento de su emisión fueron una oportunidad didáctica, un artefacto cultural de enseñanza que debía ser contextualizado, completado y revisado por quienes vivieron esos acontecimientos.

\section{SEGUNDA GENERACIÓN: COMPLETAR Y ENTENDER}

Los participantes de esta generación vivieron el golpe de Estado y la dictadura en su infancia y adolescencia, por lo cual sus recuerdos de la época son parciales, fragmentarios y difusos. También son confusos y contradictorios, pues muchos crecieron entre verdades a medias y silencios, con el fin, en muchos casos, de protegerlos. Es así que a nivel individual, las ficciones televisivas sobre el pasado reciente en Chile, al igual que otros relatos 
ficcionales sobre pasados recientes difíciles, traumáticos o conflictivos para ellos, fueron una manera de completar los vacíos que muchos sienten que tienen sobre el periodo $\mathrm{y}$, fundamentalmente, conciliar sus propios recuerdos personales con los acontecimientos históricos de la época. Esto pues, y como lo explica Jelin (2002), el pasado deja huellas «mnésicas» que no son memoria, ya que para serlo, deben ser evocadas y ubicadas en un marco que les dé sentido. $\mathrm{Y}$ es lo que ofrecieron las series.

Este ejercicio les permitió «dar forma al trauma, lo modelan, de alguna manera lo domestican y hacen comprensible al integrarlo a un relato» (Sánchez, 2016: 41), puesto que se trata de una generación que creció con miedo, sobre todo al espacio público (recuerdan las protestas, la represión en las calles a veces porque les tocó estar allí, otras veces porque no los enviaban al colegio esos días o porque estaban encerrados en casa), con desconfianza incluso de sus mismos vecinos, pues habían aprendido que cualquiera de ellos podría delatarlos, y también de las instituciones. Al respecto, dice una entrevistada: «Mientras Juan llama por teléfono a Claudia [Los 80] y estamos en toque de queda y pasa un tanque por la calle, no es que le dijo nada, es solo el miedo, no le dijo nada, es el miedo todo el rato» (Mujer, C2).

Salvo su propia familia, no podían contar con nadie, por lo que muchos crecieron aislados de su entorno. Otros trabajos recientes sobre Chile ofrecen información sobre la «segunda generación» cuando se analiza la «transferencia del miedo» y los «recuerdos inquietantes» (Jara, 2012 y 2016, en Frei, 2015: 11) y es parte de lo que quienes crecieron en dictadura recibieron.

$\mathrm{Y}$ es que, como lo han señalado otros autores, al trabajar con los recuerdos de esta generación, «para aquellas personas que experimentan la infancia o la adolescencia durante la dictadura, el miedo era el tema más importante al narrar el pasado» (Frei, 2015: 47), y en nuestras entrevistas y grupos focales es el sentimiento más arraigado durante ese periodo cuando se refieren al espacio de la calle, sin embargo, también valoran la seguridad proporcionada por sus familias y recuerdan con añoranza su vida cotidiana de infancia.

A nivel generacional, las personas con las que conversamos en los grupos focales coinciden al decir que este tipo de producciones ficcionales hacen evidentes los contrastes de su niñez. Las series los llevan de vuelta a ese periodo de sus vidas, a la protección de su familia, a sus amigos y recuerdos queridos de infancia, pero también vinculan esas vivencias con lo que estaba 
ocurriendo fuera de sus casas y que no podían ver en televisión (que era el medio más cercano para ellos). Ambas experiencias solo son conectadas en los relatos de las entrevistas, donde la emoción y la catarsis priman. Al respecto, un entrevistado señala: «Con el tema de la Claudia, ahí se ve cómo ella empieza a empaparse del proceso político que se está viviendo en la serie y como bien pasaba cuando yo era chico, pero en mi casa no se hablaba de política, pese a que mi papá es de izquierda, era tabú hablarlo porque era peligroso que alguien te escuchara. Se sabía que había sapos por todos lados y entonces se ve como muy bien reflejado en la serie con lo que le pasa a la Claudia, y cómo va viendo lo que sucede, cuando va a la $\mathrm{U}$ y se entera de muchas cosas, que es donde uno se enteraba (...)» (Hombre, ABC1).

La discusión generada en la esfera pública a raíz, entre otras cosas, de la emisión de estas series en televisión les permitió compartir con otros estas vivencias y descubrir que habían sido similares. En nuestros grupos focales aparecen los recuerdos de infancia asociados a la identificación y reconocimiento de los espacios y de experiencias comunes vinculadas a la vida de barrio y a la televisión (que es parte de los recuerdos de esa época, dejando en evidencia una alta cultura televisiva), de hecho, los acontecimientos históricos más recordados fueron aquellos que aparecieron en la televisión de la época: la visita del papa a Chile, o el triunfo de Cecilia Bolocco como Miss Universo, entre otros. Las violaciones a los derechos humanos están desconectadas de sus recuerdos quizás, porque estas imágenes como tales aparecen recién en sus registros para la campaña del No, cuando ya estaban al final de su adolescencia o ingresando a la universidad, aunque muchos habían escuchado o sabían por otras fuentes sobre las violaciones a los derechos humanos cometidas durante la dictadura.

Crecer sin imágenes de la violencia ejercida por los agentes del Estado los deja sin recuerdos o huellas de la misma, por lo que acceder a ellas es muy duro y muchos simplemente optaron por no ver las escenas o series en que estas eran más explícitas, como en Los archivos del Cardenal o en Ecos del desierto. Una entrevistada lo expresa así: «Es que la única imagen que me acuerdo de Los archivos del Cardenal es haber visto a alguien que le estaban sacando la cresta en una silla y que lo estaban torturando y que yo no fui capaz, dije no, no estoy para..., no puedo, y es que vi el capítulo y un poco del capítulo, y no pude más» (Mujer, ABC1).

El recuerdo adquirido, que es el resultado de lo que yo puedo recordar por mí mismo, es el que está asentado en la memoria de esta generación y es un 
recuerdo parcial alimentado por el recuerdo conversacional que «transmite no solo historias sobre el pasado, sino también "silencios sobre el pasado"» (Frei, 2015: 16). Entre los aspectos que se transmitieron de esta forma, aparecen de manera no muy directa tres aprendizajes: la existencia de una profunda división ideológica entre los chilenos, de la que es mejor no hablar; la desconfianza hacia las instituciones públicas y la idea de que cada uno debe arreglárselas por sí mismo.

Aunque en general reconocen que, salvo las personas que tuvieron familiares que sufrieron la represión no contaban con mucha información sobre lo que estaba sucediendo en el país y que su principal ventana al mundo eran las pantallas de la televisión, algunos de ellos cuentan con mucha información documental sobre el periodo, sin embargo, la ficción audiovisual presentada cumple un papel importante, puesto que cuenta historias que conectan lo cotidiano con lo social e histórico, por lo cual les permiten cerrar un ciclo emocional, ubicar sus propias emociones en contexto y hacer el duelo de su infancia intervenida. Esto es parte de lo que se ha llamado posmemoria afiliativa, donde tiene lugar una identificación horizontal intrageneracional (Hirsch, 2008).

A nivel intergeneracional, señalan que gracias a las series es posible aprehender el contexto y las transformaciones de la época, por ejemplo, en relación con la incorporación de la mujer al trabajo y, por tanto, la modificación de la vida cotidiana y la familia; pero también entender a sus propios hijos y sus motivaciones para, entre otras cosas, salir a la calle a protestar. Lo indica así una participante: «No era que uno viviera en una burbuja es que todo era restringido, porque los diarios eran manejados, las radios y la TV no podían trasmitir lo que quisieran. No era que uno viviera en una burbuja porque quisiera vivir en una burbuja, es que ibas para fuera de Chile y tenías otra información de lo que pasaba en Chile que la que tú sabías» (Mujer, Focus).

Muchos vieron las series con sus hijos pequeños y compartieron con ellos parte de su vida cotidiana y el impacto de la dictadura en su adolescencia; sin embargo, pocos hablaron de sus emociones y muchos menos de política con ellos. En este proceso, esta generación se reconoce, de manera no explícita, como observadora o testigo (de lo que vivieron sus padres y de lo que viven sus hijos), pero nunca como protagonista.

En síntesis, para esta generación las series presentan una versión del pasado, vinculada con su niñez que les permite recordar y situar estos recuerdos 
en un marco de comprensión mayor, al incorporar datos de contexto que les ayudaron a entender sus propias vivencias. Las series les muestran la crudeza de la represión y no todos quieren ver ese tipo de imágenes a las que no tuvieron acceso cuando eran pequeños, puesto que su ventana al mundo era la televisión, que no mostraba lo que estaba ocurriendo (hasta su presentación en la franja del No, durante la campaña del mismo nombre). Las series así les permiten conectarse con sus propias emociones y al conversar con otros de su misma generación, descubren que comparten procesos de búsqueda relativamente similares. También operan como una clave de lectura que les permite entender a sus padres y a sus hijos, aunque también los primeros son cuestionados e interpelados desde el afecto y la comprensión.

\section{TERCERA GENERACIÓN: EQUILIBRAR Y EMPATIZAR}

En el caso de los entrevistados más jóvenes, el análisis arrojó que la mayoría de los participantes contaba con muy poca información sobre el periodo representado al momento del visionado de las series, por lo que, en no pocas ocasiones, las ficciones se transformaron en una de las primeras vías de entrada a un pasado histórico y familiar complejo. Las excepciones estuvieron dadas por el acceso a algunas referencias tomadas de relatos de parientes cercanos, más marcadas solo en los casos en los que el entorno familiar de los participantes sostuvo un posicionamiento político más duro y menos conflictuado internamente. No obstante, para todos, las series marcaron una apertura hacia una dimensión relativamente desconocida de la historia común y de la conformación del sí-mismo de una identidad colectiva. Al respecto, indica un entrevistado: «La verdad es que en el colegio no se pasa mucho sobre la dictadura, creo que falta un poco más introducirnos en la malla de historia de Chile, porque son súper importantes para el país. Por eso es que nosotros vimos la película (serie), porque consideramos que era necesario para analizar un poco más nuestra historia» (Hombre, C3).

La investigación no dio cuenta de lecturas homogéneas. Sin embargo, pese a que presentaron variaciones en las lecturas efectuadas, es posible hablar de rasgos comunes que se imbrican en una perspectiva generacional, en la que confluyen experiencias de una misma etapa del ciclo de vida, en un entorno material, contextual y epocal común (Álvarez, 2018a; 2018b). Por otra parte, no se registraron grandes diferencias entre los entrevistados asimilables a su género o a su nivel socioeconómico, pero sí aparecieron algunas asociadas al 
posicionamiento ideológico de los padres y a las experiencias de cercanos durante la dictadura.

Además, es importante destacar que el visionado de las series por parte de los jóvenes fue realizado junto a familiares u otros adultos cercanos, que por su experiencia de vida o por contar con más recursos secundarios sobre el periodo, pudieron complementar, matizar o contradecir lo visto en pantalla por los entrevistados. De ahí que uno de los principales hallazgos de este estudio, pero también una de sus principales fronteras, se encuentre relacionado con las posibilidades que ofreció el visionado intergeneracional al conjunto de las ficciones a la hora de construir memorias colectivas más complejas.

Todos los entrevistados sin distinción indicaron que el visionado de las series facilitó que los padres o abuelos se dispusieran a conversar sobre el periodo y sobre sus propias experiencias, relacionadas con la vida cotidiana en la época y la situación política. Estas conversaciones permitieron a los entrevistados no solo comprender mejor el periodo histórico representado por las series, sino además entender cómo se inscribe la historia familiar en la historia nacional compartida, y cómo ellos mismos como sujetos fueron perfilados por dinámicas familiares y sociales atravesadas por esos procesos y experiencias que ellos desconocían. Una entrevistada dice al respecto: «Era bastante emotivo [...] que mis papás en ese caso dieran sus opiniones, que se abrieran y entregaran sus recuerdos y dijeran exactamente eso pasó así y es que para mí la serie fue muy importante» (Mujer, C2).

Según plantea Aleida Assmann (citada en Baer, 2010), es posible distinguir tres tipos de memoria social. El primero, al que llama memoria comunicativa, tiene lugar a partir de las experiencias de la vida cotidiana, está basado en la interacción discursiva entre los individuos y, por ende, es el que está dotado de una mayor carga emocional. Un segundo nivel es el de la memoria colectiva, más estable, delimitado y duradero, en donde las narraciones son convertidas en mitos y los acontecimientos en arquetipos. Y el tercero es el de la memoria cultural, en donde se produce la institucionalización de esos relatos, transmitidos ahora a través de soportes de conocimiento sobre el pasado y relevados, por tanto, de la sobrevivencia de portadores vivos de los discursos.

Desde esta perspectiva, el visionado conjunto de las ficciones permite la complejización del proceso de construcción de memorias, en la medida en que el relato recibido desde la televisión como memoria cultural se convierte en un 
catalizador de la construcción de memorias comunicativas. Pero, además, su presencia resulta clave para que esto último tenga lugar, puesto que se trata de un pasado en muchos aspectos traumático para quienes lo experimentaron, y cuya evocación había resultado bloqueada en la interacción entre padres e hijos. A partir de estos dispositivos de memoria cultural, toma forma lo que Hirsch (2008) llamó una «postmemoria» en esta tercera generación, formulada ya no a partir de la experiencia directa, sino que completamente mediada por los relatos recibidos.

La conversación intergeneracional además se revela como un indicador importante para los entrevistados a la hora de considerar y ponderar las propuestas discursivas de las series. Pues, aunque todos los entrevistados atribuyeron a las ficciones sentidos informativos y pedagógicos, considerándolos de manera realista y verosímil, y enfatizando así su función educativa, las lecturas negociadas (Hall, 1980) que realizaron de algunos de sus aspectos resultaron propiciadas, precisamente, por esas conversaciones intergeneracionales. Lo anterior se produjo en la medida en que, además, los entrevistados carecían de muchas otras referencias sobre el periodo con las cuales confrontar los relatos de las series, independientemente de sus características de género o de estrato socioeconómico.

En esta generación se produjo una tendencia a buscar coherencia entre los relatos recibidos del entorno cercano y las ficciones, mostrándose los discursos más persuasivos en tanto se produjeron coincidencias entre ellos, generándose «una suerte de efecto de resonancia» (Chicharro, 2011: 185) cada vez que los espectadores mayores reconocieron en las ficciones elementos que pudieron identificar como comunes a su propia historia y que favorecieron sus procesos de evocación. Así, el rigor de los relatos ficcionales de las series pasó por su evaluación en relación con ese correlato familiar, mientras al mismo tiempo, las coincidencias también permitieron validar los discursos orales de familiares y cercanos, certificándolos. Así lo indica una entrevistada: «Ver estos hechos con más sustento, donde te van contando una historia, lo hace mucho más importante. [...] que tus mismos padres y abuelos te digan así fueron las cosas, te da confianza, uno les cree» (Mujer, C2).

Por otra parte, la mayoría de los entrevistados distinguió que lo que las series muestran es solo una perspectiva más entre otras que abordan el tema. Pese a ello, hubo un rechazo generalizado a las violaciones a los derechos humanos representadas en las series. El énfasis puesto por las ficciones en el dolor de quienes vivieron experiencias asociadas al conflicto social y político 
resultó particularmente impactante para los entrevistados. Pues, todos ellos, sin excepción, independientemente de sus características socioeconómicas y de género, pero también de las inclinaciones políticas que manifestaron como propias o de sus familias, y de si contaban o no con experiencias cercanas de persecución política, señalaron haber sentido especial afección frente a las escenas de esa represión no experimentada.

Así, sus lecturas de las series operan desde el afecto (empatizar) y su percepción de esa época medida desde su experiencia del presente. Salvo en algunos pocos casos, su conocimiento sobre la época está basado en lo que los distintos medios les han mostrado y las series son un documento más del que pueden aprender, a pesar de reconocer su carácter ficcional, en un intento por buscar más ángulos en la discusión sobre la dictadura (equilibrar).

\section{CONCLUSIONES}

La relación entre ficción televisiva, historia y construcción de memorias es compleja. En todos los casos se trata siempre de reconstrucciones, de trabajos con fragmentos, como un espejo que se rompe y luego debe ser reparado. Las trizaduras quedan, dirá Ramírez (2013), haciendo evidentes las grietas y fisuras que persisten en la sociedad chilena al referirse a su pasado dictatorial reciente. Esto mismo ocurre en su proceso de transmisión intergeneracional, puesto que no solo se comparten los recuerdos, sino también los silencios y los vacíos.

En la transmisión de memorias intergeneracionales de estas tres generaciones observamos continuidades, rupturas y también algunos saltos. Entre la primera y la segunda generación vemos que existe una ruptura en la transmisión directa de lo acontecido, por protección, fundamentalmente. La transmisión se produce cuando ya ha pasado un tiempo desde la ocurrencia de los acontecimientos traumáticos. Lo que transmiten a nivel indirecto a través de silencios y evasiones, que son emociones y formas de operar en el mundo, básicamente transmite desconfianza hacia la esfera pública.

En esas condiciones existe una ruptura en la transmisión de la segunda a la tercera generación, puesto que la segunda ya crece en un contexto completamente distinto a la anterior, por tanto, su mirada sobre el pasado es diferente a la de sus padres. Para ellos, no existe un colectivo al que acudir si 
tienen necesidades, las que deben ser resueltas de manera individual y la política es un aspecto que deben rechazar, puesto que es fuente de problemas. Por tanto, la mejor manera de proteger a los suyos es mantenerlos alejados del espacio público (que fue la forma en que sus propios padres los protegieron) y darles herramientas (educación) que les permitan tener habilidades personales para responder a los requerimientos del mundo actual.

Gracias a distintos artefactos culturales (como las series televisivas, aunque no solo ellas), la tercera generación se nutre de los relatos y experiencias de la primera generación (de sus abuelos) y se tiende un puente con la segunda, con sus padres. Sin embargo, esta tercera generación también es distinta y quiere formarse su propia opinión. En ese sentido, es más autónoma, respeta la experiencia de las otras generaciones, pero sabe que están transmitiendo una versión de lo ocurrido y ellos quieren tener el cuadro completo. Como su contexto de crecimiento es distinto, ya no heredan el miedo y pueden completar los silencios y vacíos accediendo a otras fuentes de información.

En este sentido, la ficción provee de imágenes (que muchas veces ya han circulado en otras producciones audiovisuales) que operan como respaldo de la época, pero sobre todo propone marcos de interpretación del pasado que pueden ser cuestionados o validados por cada generación de acuerdo a: a) sus propios recuerdos o huellas, es decir, a lo vivido directamente; b) la etapa de desarrollo (ciclo de vida) en la que se encontraban al momento en que se produjeron los acontecimientos y en la que se encuentran al momento del visionado de las series; c) sus conocimientos previos y sobre todo lo significativo que sean estos, y c) el clima de época, es decir, el contexto sociohistórico en el que se realiza el proceso de interpretación de ese pasado ficcionado.

La ficción como formato simplifica la comprensión del pasado reciente, al ofrecer un marco de interpretación que integra lo cotidiano con lo público/político. El desafío de estos productos ficcionales es significativo, puesto que al mismo tiempo deben generar el reconocimiento e identificación de las generaciones que vivieron estos acontecimientos y acercarse a las generaciones que no cuentan con esa experiencia.

A nivel de sociedad, junto con estimular la producción de estos artefactos de memoria, se debe «dejar abierta la posibilidad de que quienes [los] "reciben" le den su propio sentido, reinterpreten, resignifiquen $-\mathrm{y}$ no que 
repiten o memoricen-》 (Jelin, 2002: 126), que es lo que deben aprender las primeras generaciones en relación con las que siguen. En este mismo sentido, las distintas instituciones de la sociedad también tienen un rol que cumplir, puesto que no solo deben entregar conocimientos, sino que más bien compartir marcos de interpretación en los que estos tengan un sentido, generando entonces aprendizajes significativos para la conformación del propio relato de vida, para contribuir así a la construcción de memoria colectiva.

En síntesis, la recepción de estas series se transformó en una instancia deliberativa intergeneracional para la mayoría de los participantes de nuestro estudio. Este espacio de deliberación estuvo caracterizado, principalmente, por la controversia política que las series propiciaron. Por ejemplo, los temas más discutidos fueron la representación de las violaciones a los derechos humanos, la omnipresencia de la dictadura en los años $80 \mathrm{y}$ el rol subyugado de la mujer en aquella época. Estos temas tensionaron a cada una de las generaciones en un proceso activo de recepción televisiva, que propició la construcción de memoria intergeneracional sobre el pasado reciente de Chile.

RECIBIDO: 11 DE NOVIEMBRE DE 2019

ACEPTADO: 17 DE ENERO DE 2020

\section{BiBLIOGRAFÍA}

Álvarez, C. (2018a). La perspectiva generacional en los estudios de juventud: enfoques, diálogos y desafíos. Última Década, 26(50), 40-60. . (2018b). Lo juvenil y el género: pistas para su abordaje. En: C. Duarte y C. Álvarez (Eds.), Juventudes en Chile. Miradas de jóvenes que investigan (pp.48-69). Santiago: Andros Impresores/Facultad de Ciencias Sociales Universidad de Chile.

ANDERSON, B. (1993). Comunidades imaginadas. Reflexiones sobre el origen y la difusión del nacionalismo. México, D.F.: Fondo de Cultura Económica.

ANTEZANA, L. (2015). Televisión y memoria: a 40 años del golpe de estado en Chile. Comhumanitas, 6(1), 188-204. 
Antezana, L. y CABAlin, C. (Eds.) (2016). Audiencias volátiles. Televisión, ficción y educación. Santiago: Universidad de Chile. . (2017). El precio del consenso. La dictadura en la ficción televisiva chilena. Chasqui. Revista Latinoamericana de Comunicación, 136, 249262.

. (2018). Memorias en conflicto en la esfera pública chilena: ficción televisiva y dictadura. Anàlisi. Quaderns de Comunicació i Cultura, 58, 105-119.

Antezana, L. y SAnta Cruz, E. (2016). Tecnología y poder: simulacros de participación política. En J. P. ArAnciBia y C. SAlinAs (Eds.), Comunicación política y democracia en América Latina (pp. 125-140). Barcelona: Ediciones Ciespal-Gedisa.

BAER, A. (2006). Holocausto. Recuerdo y representación. Madrid: Losada. - (2010). La memoria social. Breve guía para perplejos. En J. A. Zamora y A. SuCASAs, Memoria-Política-Justicia. En diálogo con Reyes Mate (pp. 131-148). Madrid: Trotta.

Bourdin, G. (2016). Antropología de las emociones: conceptos y tendencias. Cuicuilco, Revista de Ciencias Antropológicas, 67, 55-74.

Bradley, E. H., Curry, L. A. y Devers, K. J. (2007). Qualitative data analysis for health services research: Developing taxonomy, themes, and theory. Health Services Research, 42(4), 1758-1772. DOI: http://dx.doi.org/10.1111/j.1475-6773.2006.00684.x

Braun, V. y Clarke, V. (2006). Using thematic analysis in psychology. Qualitative Research in Psychology, 3(2), 77-101. DOI: http://dx.doi.org/10.1191/1478088706qp063oa

Castillo, A. M., Simelio, N. y Ruiz, M. J. (2012). La reconstrucción del pasado reciente a través de la narrativa televisiva. Estudio comparativo de los casos de Chile y España. Revista Comunicación, 10, 666-681.

Chicharro, M. (2011). Aprendiendo de la ficción televisiva. La recepción y los efectos socializadores de «Amar en tiempos revueltos». Revista Comunicar, 36, 181-189.

CONTRERAS, D. y MacíAs, V. (2002). Desigualdad educacional en Chile: Geografía y dependencia. Cuadernos de Economía, 39(118), 395-421. 
DÁvilA, O. y GHIARDo, F. (2018). Trayectorias sociales como enfoque para analizar juventudes. Última Década, 26(50), 23-39.

DENZIN, N. K. (2001). The reflexive interview and a performative social science. Qualitative Research, 1(1), 23-46.

DurÁn, C. (2016). Levels of Depth in Deep Disagreement. En Proceedings of the 11th OSSA Conference. University of Windsor: SicSat 2016 (forthcoming).

FELD, C. (2010). Imagen, memoria y desaparición. Una reflexión sobre los diversos soportes audiovisuales de la memoria. Revista ALETHEIA, 1, $1-16$.

FOCÁs, B. (2014). Del funcionalismo al consumo multitasking. Límites y potencialidades de los estudios de recepción. Astrolabio, 12, 338-364.

FREI, R. (2015). The living bond of generations. The narrative construction of post-dictatorial memories in Argentina and Chile. (Tesis Doctoral). Berlín: Facultad de Filosofía, Universidad de Berlín.

Greene, J. C. (2007). Mixed methods in social inquiry. San Francisco, CA: Jossey-Bass.

GrossberG, L. (2009). El corazón de los estudios culturales: Contextualidad, construccionismo y complejidad. Tábula Rasa, (10), 13-48.

Halbwachs, M. (2004). La memoria colectiva. Zaragosa: Prensa Universitaria de Zaragoza.

. (1995). Memoria colectiva y memoria histórica. Reis(69), 209-219.

Hall, S. (1980). Codificar/Decodificar. En Culture, Media, Language. Working Papers in Cultural Studies (pp. 129-139). Londres: Hutchinson.

Hirsch, M. (2008). The generation of postmemory. Poetics today, 29(1), $103-$ 128.

Hoskins, A. (2014). The mediatization of memory. En K. LundBY (Ed.), Mediatization of Communication (pp. 661-679). Londres: De Gruyter Mouton.

Jauss, H.-R. (1978). Pour une Esthétique de la Réception. París: Gallimard.

JELIN, E. (2001). Los trabajos de la memoria. Madrid: Siglo Veintiuno Editores. 
. (2014). Las múltiples temporalidades del testimonio: el pasado vivido y sus legados presentes. Clepsidra. Revista interdisciplinaria de Estudios sobre memoria, 1, 140-163.

RAMíREZ, R. (2013). Escenas de una realidad trizada: el documental chileno de la postdictadura. (Memoria de Título). Recuperado de: http://bibliotecas.uchile.cl/documentos/20130703-1111escenas de una realidad trizada.pdf

Reulecke, J. (2008). Generation/Generacionality, Generativity and Memory. En A. ERLl y A. NÜNNING, Cultural memory studies: an international and interdisciplinary handbook (pp. 119-125). Berlín: Walter de Gruyter.

SÁNCHEZ, R. (2016). La ficción televisiva como recurso para la deliberación sobre el pasado. Revista Luciérnaga/Comunicación, 8(16), 38-47.

SANTA CRUZ, E. (2017). Derrotero histórico, tendencias y perspectivas de la TV chilena. Comunicación y Medios, 35, 8-21.

SARLO, B. (2004). Historia y Memoria. ¿Cómo hablar de los años setenta? En N. RICHARD (Ed.), Revisar el pasado, criticar el presente, imaginar el futuro (pp. 33-50). Santiago de Chile: Universidad Arcis.

SAuTu, R. (2004). Estilos y prácticas de la investigación biográfica. En El método biográfico. La reconstrucción de la sociedad a partir del testimonio de los actores (pp. 21-61). Buenos Aires: Lumière.

SCHLOTterbeCK, M. (2014). Actos televisados: el Chile de la dictadura visto por el Chile del Bicentenario. A Contracorriente, 12(1), 136-157.

WALDMAN, G. (2009). Chile: la persistencia de las memorias antagónicas. Política y Cultura, 31, 211-234. . (2014). A cuarenta años del golpe militar en Chile. Reflexiones en torno a conmemoraciones y memorias. Revista Mexicana de Ciencias Políticas y Sociales, 221, 243-266.

Wolton, D. (Ed.) (2001). A la recherche du public. Réception, télévision, médias. París: CNRS Editions. 